\title{
Classroom Practice to Translate Classical Chinese Poetry
}

\author{
Huifang $\operatorname{Tian}^{1}$ \\ ${ }^{1}$ School of Foreign Languages, China University of Petroleum, Beijing, China \\ Correspondence: Huifang Tian, School of Foreign Languages, China University of Petroleum, Changping \\ District, Beijing, 102249, China. Tel: 86-010-8973-3013, 86-131-6750-7662. E-mail: hftian2000@aliyun.com
}

Received: September 3, 2013 Accepted: September 25, 2013 Online Published: November 5, 2013

doi:10.5539/elt.v6n12p129 URL: http://dx.doi.org/10.5539/elt.v6n12p129

\begin{abstract}
English-Chinese (E-C) translation is part of tertiary curriculum and is generally text- or reading-based, and any course in relation to it is meant to develop the competence of reading, on a higher level, from a language comparative perspective. Chinese-English (C-E) translation is deemed by many as a productive skill, possible when the overall language competence is achieved, but little is accomplished to be developed on its own. In the classroom C-E translation is conducted to consolidate the lexical or grammatical items learned from reading texts. This study focuses on C-E translation of poetic discourse, drawing classical Chinese poetry as the research material. It underlines this literary genre as prompt to promote language learning, through detailed language comparison and analysis. The learning activities are based on discussion of poetic features and fulfilling tasks of poetic components. The process indicates a keener sense of literary works and growing awareness of poetic features which work positively toward language production and appreciation.
\end{abstract}

Keywords: classical Chinese poetry, translation, classroom, practice

\section{Introduction}

In classroom practice, the difficulty of translating classical Chinese poetry is two-faceted: the comprehension and interpretation and the attempt to put a piece into a similar verse-like text. The ancient poems were written hundreds of years ago, filled with expressions of archaic Chinese, it is then often a hard job to explain the classical expressions in modern terms and rearrange them into up-to-date expressions. The re-writing form of translation consists of symmetric structures, antithetic words with end-of-the-line or inside-line rhymes. Some people argue that the job of a translator is a job of a writer, and this is especially true of a poetry translator. In the translation of ancient Chinese poetry master translators are only a few specialists in both languages. To the mind of the most language learners poem translation seems a far cry, only very vaguely related to them. Although it takes a language specialist to translate poems, the language teacher and the learners can work together and put out meaningful efforts towards poetry appreciation and translation, from the perspective of language learning and vision extending. Doing classical translation can be a new form of English learning since it gives the learner an opportunity to compare language features and ultimately to figure out the ways in which languages differ and the ways in which they are similar. (Vikner, 2006). Learners can make use of poems already translated and observe how the expert translator has interpreted the source poem and how (s)he has arranged the lines. The pre-translation reading comprehension is actually done through two languages, one preliminary, and the other structural, both of which show features of comparative linguistics.

Poetry study and research in China are usually concerned with aesthetic analysis, with the result that only the linguistic gurus' translations are analyzed, appreciated and followed as criteria and models, and there's scarcely any room for the learners' participation. This approach does little to promote the grassroots' interest in appreciating or translating this type of poetry. In Chinese high schools learners are not much motivated by classical Chinese poetry learning in the classroom, where all they have to do is listen to the elaboration on every aspects related to a particular poem (Song 2005). The shift to the students' involvement, particularly by intermediate and advanced level college students, does indicate a positive change. Though inexperienced and new to the tasks, college learners have the capacity to invest quality time and efforts in the classroom, where they have teachers' guidance and peers' help. They are willing to take up tasks, which are incorporated with the other skill development.

Unlike E-C translation, where learners still are able to learn through the reading comprehension, they may not 
feel much learning with C-E translation; all they are required to do is demonstrate whatever their productive skill they have. To compensate this drawback, learners are given as much time observing specialists' translations as they do their own, to take up separate tasks instead of full poem translation. In this process they are observing features of poetry, building awareness of this new literary form and learning English through translation. And assuredly they have much to learn and prepare before becoming competent translators.

But what's happened to this type of translation? Deterding (2013) claims that in translating classical Chinese poetry one must be aware of eight areas of loss, including rhyme, meter, compact style, allusions. The loss presents gaps not just in language, but also in culture, history, and customs. It is hard to fill up the gaps but possible to narrow them and amend the losses in other ways. This is one area of awareness to be raised on the part of the learners. It is awarding for them to acquire such a sense for translation in either way. In comparing literary forms and meaning in poetry between the two languages, the learners learn the basic forms and measures which prepare them to do poetry translation on their own, for their professional or self-entertaining interest. The following section of this paper looks at the comprehension, interpretation and translation of classical Chinese poetry in the areas of structure, meaning, rhyme, image, around which the class discussion takes place and small tasks get tackled. In the discussion below the study focuses on classroom activities that help build confidence and competence in interpreting and translating the type of poetry.

\section{Method}

\subsection{Two-Way Comprehension}

In the classroom setting the comprehension of the classical poetry takes place both in Chinese and in English. Learners work on tasks expressed both in languages. Learners benefit from the lecturer's introduction of the poet in Chinese, and from reading the target translation of the poem later on. The two-way comprehension facilitate interpretation, both in form and meaning, and compensate gaps of understanding involved in the ancient style of expressions, the format, and the combination adds to insight into source poem and the target translation. Straight (1981) believes that the profound knowledge of the translator is the key to the success of the translation; a lack of source language system and cultural context handicap source-poem comprehension, and the same thing can be said of the target translation.

\subsubsection{Annotations}

Notes provide the terminology in Chinese and note content in English, to fill up gaps of comprehension concerning the background, relation, allusion, structure of the poem. The learners are encouraged to choose their area of comprehension gap. Below are two lines from a poem by $\mathrm{Xu} \mathrm{Fu}$, and the type of adapted annotation.

双飞燕子几时回, 夹岸桃花蘸水开。

Table 1. Annotations

1) Author \& background: A poet in Song Dynasty, nicknamed Dong Hu Ju Shi, poet of the East Lake; was born in modern-time Xiu Shui County, Jiang Xi Province

2) Allusion \& expressions: 夹岸桃花/酸水开, somewhat archaic expressions, suitable for literary writing of the time.

According to Xu, Tang, and Shen (2004, p. 118), annotation facilitate readers' comprehension and their decision as to rhyme, meter, and other aspects, because accurate translation is based on adequate comprehension.

\subsubsection{Discussion Questions}

Such questions help to identify the poet's background, the format of the poem and expressions. Questions set this way are particularly relevant to pre-translation work, and help the teacher present the main items of the translation activities. In this particular case, the questions may be centered on the poet's nickname (poet of the East Lake), his literary connection (Ju Shi - dweller) and comparison of Chinese and Western poets. They also serve to elicit response to the poetry characteristics in terms of structural similarities to and differences from non-poetic discourse.

\subsubsection{Comparison with the Translation}

This practice is meant to assist comprehension from another perspective. Questions are put in Chinese to evoke a comparison with the translated expressions. 
a) 候鸟在哪里过冬? (cf. swallow fly back again)

b) 为何不说两岸桃花? (cf. peach blossoms on both shores)

c) 人不渡指的是诗人自己还是大家? (cf. I cannot cross the bridge)

d) 诗中是否表达了喜悦? (cf. what joy to see ...)

Overall, classical Chinese poems are strict in format, with same-character lines. There are five-character-line and seven-character-line poetry. The rhyme schemes are more or less regular. Rhyme and symmetrical expressions are important elements to produce harmonious and musical effects. Another distinctive feature is the pastoral theme, an aesthetic value predominant in the majority of the ancient poems. The expression of personal feeling is common, usually on the beautiful landscapes, personal relations, and sometimes on political issues, which is never an open discussion or given free rein to. In translation, it is impossible to reproduce the five-, seven-character lines, the original perfect symmetrical phrases or couplets. But it is possible reproduce the images, which is noteworthy component in Western poetry. In the Chinese poems the image concept consists of the noun or noun phrase, and the action verbs, i.e. hills, rivers, grass, trees, sky, the moon; ascend/descend, cross, see, watch, smell, touch, observe. The image concept becomes the center of the poem, while the action maker "I", "we" are either implied or seem marginalized. In translation, however, both the action maker and the image concept are to be stated clearly and explicitly. This gives the translator a tough job: to maintain the original poetic feel and make the matter clear. A classical Chinese poem appears to SHOW the reader something, while the translation - and the Western poetry as a whole - seems to TELL something to the reader.

\section{Interpretation}

As each reader may interpret a poetic point from his/her own point of view, based on personal experience, interpretation in another language will vary, from person to person. Gu (1989) proposes variety of criterion in translation, and their inter- compensability in nature. Robinson (2001) accepts both rational and non-rational concepts, seeking a "middle-field" between rational, "perfect" translation and non-rational, non-perfect in translation. In learning to translate classical poems, both the teacher and the students are learners, beside the master translators. Since the masters are few, and learners are many, it is necessary to cultivate learners' interest in the kind of poetry and let them join the rank of apprenticeship and become excellent translators. In classroom discussion and practice, the massive task of the whole piece translation is cut into chunks of tasks, to reduce their formidability and to respond to slightly different needs of interest or development. The tasks include explanation of a line or part of it, re-translation and even attempts to re-arrange in Chinese.

\subsection{Synonym Substitution}

A substitution encourages a somewhat diversified version, using similar expressions. The following activities are based on the same poem.

a) When will the swallows pair by pair fly back (in pairs)

b) Peach blossoms on both shores just above water float. (skip; dance)

c) I cannot cross the bridge submerged by vernal rain. (sightseers; the bridge disappears)

d) What joy to see from the willow shade comes a out a boat (wonder)

\subsection{Image Substitution}

The use of a different image changes the translated lines using a bit of learners' choice of words.

a) When will the swallows pair by pair fly back again? (bring back full summer/twitter on my eaves)

b) Peach blossoms on both shores just above water float. (Lake water mirrors peach blossom ...)

c) What joy to see from the willow shade comes out a boat. (... from where wild ducks scatter)

\subsection{Adapting the Translation}

Adaptation recommends alternatives to interpret the whole four lines.

a) Is it possible to say "summer-reporting swallows"?

b) Can we say "swaying willow on both banks" instead of "peach blossoms on both shores"?

c) Is it equally good to use the active voice (Vernal rain submerged ...) in place of the passive voice adopted by the expert translators?

d) Is it possible to have the important message "out comes a boat" stands at the beginning of the line? 


\subsection{Imitation of the Source Poem}

This invites creative minds to adapt the source poem lines, to savor their own enjoyment. The attempts are supposed to lend understanding and interpretation of the poem. And other creative minds can be invited to put the adapted poem into English.

Table 2. Creating your own lines

\begin{tabular}{lll}
\hline observation & tips & your own lines \\
\hline 双飞燕子几时回 & 归 & \\
\hline
\end{tabular}

Owing to structural characteristics and syntactic orientation, the English translation differs remarkably from the source poem in (1) dealing with the subject or the speaker of the poem. In the source poem the subject is implicitly or vaguely expressed, and the one in English explicitly stated (人不渡/ I cannot cross. The reference of “人” is not quite clear); (2) Being unable to capture the original perfect symmetrical or matching phrases. In source poem, the subject and the predicate pattern in the first two lines is NP + VP, the noun phrase being made up of a verbal attribute plus a concrete noun, and the verb phrase of an adverb plus action verb.

Judged by the English criteria, one or two Chinese poem lines are neither grammatically correct nor syntactically appropriate. The third line translated literally: the vernal rain broke the bridge people cannot cross; the fourth line: a little boat rows out of the willow shade. This grammatical incorrectness is noteworthy in ancient Chinese poetry, but at the same time lends terseness and symmetry to the poetry.

The strength of the classical poetry lies in its capacity to depict natural landscape, in its perfect structure of matching lines and phrases. It is perhaps less able to narrate a process or event than its English counterpart, which is easier to learn and publicized.

\section{Rhyming and Other Rhetoric Means}

Rhyming, antithetic and parallel and expressions feature the classic poetry and are an important consideration of the translator. Zhu (2004) writes that rhymes and meters produce musical effect and pleases the ear. Rhymes and structural symmetry produce sound and musical effects. In English poetry, there are also systematic schemes of rhyme, i.e. double rhyme, triple rhyme, rising rhyme, falling rhyme, perfect and imperfect rhymes. Other poetic components such as alliteration, assonance also produce the similar sound effect. Brian Buckley (date not given) considers three relevant factors in writing rhyming poetry: consistent rhyming scheme, consistent pattern of syllables, and consistent pattern of syllable stresses. Both poetries also attach importance to rhythm, in different ways. In the Chinese poetry rhythm is realized the by producing the same-character lines or phrases, same patterns of verbal or noun phrases and the identical toning of each line-ending character. In English this is usually achieved by meters, by using phrases matching or contrasting in concept. Like song lyrics, most of the classical Chinese poems were written as music lyrics to sing to friends or entertain the royal or aristocratic circles. The people who wrote poetry recited them to his friends or associates to show off his knowledge and learning. The two-character phrase 诗歌 ( $\mathrm{sh} \bar{i}$ gē) has a collective meaning of poetry and verses, but when understood singly, one means "poetry", the other "songs". Although modern poetry in both languages tend to associate with free expression of meaning more than rhyming schemes, it is essential to make learners aware that rhymes are actually a basic language feature to give a balanced structure in English, like many of the rhymes for children's learning. Foreign language learners also benefit from learning rhyming phrases, which are musical and help memorize the target material. One way to help the learners learn to write rhyming words is to get them to observe many rhyming word pairs in English prosaic and lyrical expressions and build up their awareness.

\subsection{Observing Rhyming in Non-Literary Genres}

Such observation means to build up the learners' awareness of rhyming in English language. According Wang (2010), song lyrics have rhyming patterns very similar to poetry, and that a study of such patterns may increase awareness of rhyming of non-literary genres.

\subsection{Practicing End-Line Rhyming}

End-line rhyming means adapting original end-of-the-line words, using words recommended by the teacher.

When will the swallows pair by pair fly back again?

Peach blossoms on both shores just above water float. 
I cannot cross the bride submerged by vernal rain.

What joy to see from the willow shade come out a boat.

Suggestion: Is it possible to try the words fly and sigh at the end of the first and third line, and flip, skip at the end of the second and fourth line?

Practice:

When will the swallows back again ?

Peach blossoms on both shores just above water

Sightseers, unable to pass the submerged bridge,

What joy to see from the willow shade out a boat

4.3 Matching or Antithetic Structures Is Meant to Practice Similar or Contrasting Expressions or Ideas, to Correspond to the Matching Structures of the Source Poem

For example:

As the swallows in twos are soon back to tell summer, peach blossoms in both shores are early to show spring.

(Matching in idea)

The bridge submerged, sightseers are anxious about no crossing, a boat emerged, promising a ferry to their delight and joy.

(Contrasting and antithetic in meaning)

Practice:

Sightseers, hesitant to pass the bridge submerged, . (Sigh)

A boat, ready to ferry them clear, is quick to . (Arrive)

\subsection{Alliteration and Assonance}

These additional rhyming schemes can also help produce matching sound or matching or contrasting ideas. Like the ways of practice discussed above, observation can lead the way to awareness building, and learners can translate lines practicing alliteration and assonance in their won ways.

Observation

Alliteration

back to basics/balance the books/boom or bust/do or die/green as grass/hale and hearty/the more the merrier/kill the king/pay the price

Alice's aunt ate apples and acorns around August.

Larry's lizards like leaping leopards.

Assonance

I'll lie down by the side of my bride.

Try to light the fire.

Practice: Below are another poem and the translation. From the translation find out the cases of alliteration and assonance.

离思 (lí sī) - 元稹(yuán zhēn)

céng jīng cāng hăi nán wéi shǔi chú què wū shān bū shì yūn

曾 经沧海难为水, 除却巫山不是云。

qư̆ cì huā cóng lăn huí gù bàn yáun xīu dào bàn yuán jūn

取次花丛懒回顾, 半缘修道半缘君。

Mourning for my dear departed wife

No water's wide enough when you have crossed the sea;

No cloud is beautiful but that which crowns the peak.

I pass by flowers that fail to attract poor me, 


\section{Half for your sake and half for Taoism I seek.}

Practice: translate the following lines, using suggested words in the bracket.

a) 何当共剪西窗烛 - 李商隐 (wish for a time; trim the candlelight; by the window )

b) 语多难寄反无词 - 陈端生 ( have many to express; words go away from me)

c) 远上寒山石径斜 - 杜牧 (steeply hill; stony path; chilly season)

d) 锄禾日当午, 汗滴禾下土 - 李绅 (weed my plot; hot sun; sweat drips on the soil)

In the classical Chinese poetry, apart from the end-line rhyming there is also assonance and alliteration as means to retain resonance, although they don't seems much notable methods in comparison to end-line rhymes, and they attract much less attention. The poet must have used the assonance and alliteration deliberately to achieve an echoing atmosphere. This phenomenon of assonance mostly occurs on two-character phrases, but sometimes on two far-neighbor characters. For instance,

a) 昔日龂龊不足夸 - 孟郊 (龌龊 wò chuò: each character has the vowel sound /ò/)

b) 君问归期未有期 - 李商隐 (问 wèn; 未 wèi: each character has the same consonance sound $/ \mathrm{w} /$ ).

In most studies done by Chinese scholars on the classical poetry, 谐音 (xié yīn) - roughly corresponding to assonance - is used, but there is no such term as alliteration. Neither is considered important attribute attached to poetry, probably because such cases are also very common in spoken or non-literary written Chinese.

In comparison to English poems that are metric and stress-syllable-based, classical Chinese poems reflect rhythm in same-character-line stanzas: each line consisting of identical number of character, and of identical number of characters forming NP or VP. Taking the seven-character-line and five-character-line quatrains for example. In the case of seven-character lines, the first four characters form either NP or VP, or a clause, becoming the subject, the main clause, the attribute, or adverbial, and the remaining three characters fulfill the function of the predicate, the central noun, even the central clause. The first four characters and the last three characters form two rhythmic/sense groups, each group functioning on its own. In five-character lines, the first two and the last three characters form two sense groups respectively.

Line 1: 泽国江山 入战图 (NP: the subject, VP: the predicate)

Line 4: 一将功成 万骨朽 (S+V1: expressing condition, V2: expressing result)

(Lines from the poem written by CAO Song)

Line 2: 红泥 小火炉 (NP: attribute, NP: the central noun of the line)

Line 3: 晚来 天欲雪 (NP: adverbial, S+V: central clause of the line)

(Lines from the poem written by BAI Juyi)

\section{Discussion}

For both the teacher and learners, learning to do classical Chinese poetry translation is building up language learning experience, in a different way from the previous E-C translation practice. They now assign a new way of application to their previously learned knowledge of English, and find their stock of it too limited. They realize that language is not just acquired, but also to be consciously learned and memorized, for the terse and rhyming phrases are in bad need and find ready and handy application in translating this type of poems.

Expertise on the source and target language poetry is required of the teacher, whose preparation of the short and practical class activities means the key to the success of the lecture. She/he needs not just to be a competent translator, but perhaps a poet of some rank, to help open the door to the poetry appreciation, to know the poetry and translation on a competent amateur or professional basis. In this respect, the teacher needs to acquaint oneself with other sources of the poetry writing, techniques, practitioners, methodology, to offer the class who need workable and motivating tasks.

To some extent, whether the learners feel drawn and motivated to the program depends on the tasks and activities, which need to be not only categorized and scaled, in a moderately progressive fashion, but also varied and diversified, capable of answering different needs or interest. It is possible to help learners learn the classical poetry, in the classroom setting, and on their own, since the internet is a rich resource of material for appreciation and practice.

\section{Acknowledgements}

This paper is part of a group project related to Literature Translation, financed by Petroleum University of 
Beijing, in an attempt to institute course design and reform. The author would like to express his sincere gratitude to the members of Graduate Education Section who have offered valuable advice concerning literature translation in general, and poetry translation in particular, as well as anonymous reviewers and editors at ELT for their valuable comments and suggestions.

\section{References} http://www.elfwood.com/farp/thewriting/27brianrhyming/27brianrhyming.html

Dong, J. (2006). The Intrinsic Rhythm and Translating Criterion of the Ancient Chinese Poems. Journal of Shanghai University, 13, 1.

Deterding, D. (2013). Translating Classic Chinese Poetry and Prose. Retrieved from http://wuxizazhi.cnki.net/Search/KCJY201220059.html

Gu, Z. K. (1989). On the Variety of Translation Criteria and the Inter-compensability. Chinese Translators Journal, 1, 17.

Robinson, D. (2011). Translation and the Problem of Sway. Amsterdam and Philadelphia: John Benjamins Publishing Company.

Wang, J. J. (2010). A Study on lexical Deviation in English Pop song Lyrics. Journal of Liuzhou Vocational and Technical College. Retrieved from http://en.cnki.com.cn/Article_en/CJFDTOTAL-LZJB201001016.htm

Straight, H. S. (1981). Knowledge, Purpose, and Intuition: Three Dimensions in the Evaluation of Translation, Ps. In M. Grddis Rose (Ed.), Translation Spectrum (pp. 41-42). NY: State University of New York Press.

Song, J. (2005). Methods and Approaches to the Teaching of Classical Chinese Poetry. Retrieved from http://www.59165.com/dissertation/2/10632.html

Vikner, S. (2006). Theoretical and Comparative Linguistics, Inaugural Lecture. Retrieved from http://www.docin.com/p-443652147.html

Xu, Y. C., Tang, Z. D., Shen, Z. C., \& Liu, Q. (2004). 100 Tang and Song Quatrain Masterpieces by Great Poets. Changchun: Jilin Wenshi Press.

Zhu, C. P. (2004). A Coursebook on Meters and Rhymes of Poetry. Ji Nan: Ji Nan University Press.

\section{Author}

Huifang TIAN was born in Tang Shan, Hebei Province, Mar. 1966. He received his Bachelor Degree of Art from the Department of Foreign Languages, Hebei Normal University, Hebei Province, Sept. 1989. He is Associate Professor, and currently teaching English at the School of Foreign Languages, China University of Petroleum, Beijing. His research interests include foreign language teaching and education, and English for Specific Purposes, author of several articles on language teaching and research of well-acknowledged journals.

\section{Copyrights}

Copyright for this article is retained by the author(s), with first publication rights granted to the journal.

This is an open-access article distributed under the terms and conditions of the Creative Commons Attribution license (http://creativecommons.org/licenses/by/3.0/). 